\title{
Efeito de bicarbonato de potássio sobre a severidade do oídio em plantas de soja
}

\author{
Regiane Medice ${ }^{1}$ Wagner Bettiol ${ }^{2}$ Uli Quirino de Mello Altéa ${ }^{2}$
}

${ }^{1}$ Departamento de Produção Vegetal, Universidade Estadual Paulista “Julio de Mesquita Filho”, CP 237, Botucatu, SP. ²Embrapa Meio Ambiente CP 69, 13820-000 Jaguariúna SP.

Autor para correspondência: Regiane Medice (regiane76br@yahoo.com.br)

Data de chegada: 19/02/2012. Aceito para publicação em: 15/03/2013.

\section{RESUMO}

Medice, R.; Bettiol, W.; Altéa, U.Q.M. Efeito de bicarbonato de potássio sobre a severidade do oídio em plantas de soja. Summa Phytopathologica, v.39, n.1, p.35-39, 2013.

O oídio da soja, causado por Erysiphe diffusa, é considerado uma doença esporádica podendo ocasionar perdas quando atinge proporções epidêmicas. O trabalho teve por objetivo avaliar a eficiência de bicarbonato de potássio (Kaligreen ${ }^{\circledR}$ ) no controle do oídio da soja. As pulverizações do bicarbonato de potássio nas concentrações de 0 ; $0,25 \%, 0,5 \%, 0,75 \%$ e $1,0 \%$ e do fungicida (piraclostrobina + epoxiconazole) e as avaliações foram semanais. Folhas foram coletadas para análise ultraestrutural através da microscopia eletrônica de varredura. O bicarbonato de potássio controlou a doença em todas as concentrações, mas causou fitotoxicidade a partir de $0,5 \%$. Na analise ultraestrutural pode-se observar que o produto apresentou ação direta sobre o patógeno ocasionando murchamento e redução na germinação dos conídios. O produto apresenta potencial para controlar a doença, porém deve ser adequada a concentração a ser recomenda, bem como a frequência de aplicação para evitar os problemas de fitotoxicidade.

Palavras-chave adicionais: bicarbonato, produtos biocompatíveis, doenças da soja, oídio, Erysiphe diffusa.

\section{ABSTRACT}

Medice, R.; Bettiol, W.; Altéa, U.Q.M. Effect of potassium bicarbonate on the severity of powdery mildew in soybean plants. Summa Phytopathologica, v.39, n.1, p.35-39, 2013.

The soybean powdery mildew, caused by Erysiphe diffusa, is considered a sporadic disease which can cause losses when it reaches epidemic proportions. This study aimed to evaluate the efficiency of potassium bicarbonate $\left(\right.$ Kaligreen $^{\circledR}$ ) in controlling soybean powdery mildew. Sprays of both potassium bicarbonate at concentrations of $0,0.25 \%, 0.5 \%$, $0.75 \%$ and $1.0 \%$ and fungicide (pyraclostrobin + epoxiconazole), as well as assessments, were weekly carried out. Leaves were collected for ultrastructural analysis by scanning electron microscopy. Potassium bicarbonate controlled the disease at all concentrations but caused phytotoxicity from $0.5 \%$. In the ultrastructural analysis, the product had a direct action on the pathogen, causing wilting and reduction in conidium germination. The product has the potential to control the disease, but the concentration to be recommended should be adequate, as well as the frequency of application to prevent phytotoxicity problems.

Additional keywords: bicarbonate, biocompatible products, soybean diseases, powdery mildew, Erysiphe diffusa.

Na cultura da soja, aproximadamente, 50 doenças causadas por fungos, bactérias, nematóides e vírus foram identificadas no Brasil (24) e mais de 100 doenças foram listadas mundialmente (21). Dentre as doenças, o oídio, causado por Erysiphe diffusa, requer, em algumas condições, a utilização de fungicidas para garantir a produção, caso contrário as perdas podem atingir até $40 \%$ (6).

Dentre os principais produtos alternativos testados, alguns são compostos de um ou vários sais de potássio, fosfato, sódio, silício, cálcio, argila e materiais anti-transpirantes $(9,14,18,26)$, biofertilizantes $(2,3)$, extratos de plantas $(16,23)$, óleos vegetais e sintéticos (16) e leite e soro de leite $(3,4,7)$. A combinação de mais de um método alternativo pode ter efeito aditivo ou sinergístico como foi observado por Ziv \& Zitter (26). Dentre os produtos biocompatíveis para o controle de alguns oídios, foi demonstrado que alguns tipos de bicarbonato são eficientes $(10,11,17,19,26$, 27). Também o bicarbonato de potássio é recomendado para o controle de oídio, tendo um produto registrado em diversas partes do mundo, inclusive no Brasil, denominado de Kaligreen ${ }^{\circledR}$.

Alternativas de controle e manejo da doença com produtos menos agressivos ao ambiente ou inócuos ao homem tornam-se relevantes, havendo a necessidade de buscar alternativas de baixo custo e que sejam eficientes no controle da doença. Assim, esse trabalho teve como objetivo avaliar a eficiência do bicarbonato de potássio, princípio ativo do produto Kaligreen ${ }^{\circledR}$, para o controle do oídio da soja.

\section{MATERIAL E MÉTODOS}

O ensaio foi conduzido, em casa de vegetação, no período de agosto a dezembro de 2008. No experimento foi utilizada a cultivar MGBR-46, denominada Conquista, por ser suscetível ao oídio. Em 
vasos plásticos de 5 litros de volume, contendo uma mistura de latossolo vermelho e substrato de casca de pinus ( $80 \%: 20 \%$, respectivamente), foram semeadas quatro sementes, mas deixando desenvolver duas plantas por vaso. $\mathrm{O}$ delineamento experimental constou com seis tratamentos e cinco repetições, totalizando 30 vasos. As plantas foram mantidas em casa de vegetação e no $30^{\circ}$ dia, quando as plantas apresentavam-se no estádio V4, foi realizada a primeira aplicação dos produtos.

Os tratamentos analisados consistiram das concentrações de 0 ; 0,$25 ; 0,50 ; 0,75$ e $1 \%(\mathrm{p} / \mathrm{v})$ de bicarbonato de potássio, princípio ativo do produto Kaligreen ${ }^{\circledR}$, e um fungicida (piraclostrobina + epoxiconazole) na dosagem recomendada. As pulverizações foram semanais com o auxilio de uma pistola de pintura acoplada a um compressor de ar, a uma pressão de $10 \mathrm{lb} \mathrm{pol}^{-2}$ (Toagosei Chemical Industry Co. Ltd. Japão), sendo realizadas ao final da tarde, quando a temperatura se encontrava em torno de $25{ }^{\circ} \mathrm{C}$. Durante o período de condução do experimento foi observada a incidência de mosca branca e tripes e uma pequena incidência de ferrugem asiática, mas que não comprometeram o desenvolvimento do estudo.

A inoculação do patógeno foi realizada transferindo plantas de soja infectadas com oídio para a casa de vegetação onde o ensaio estava sendo conduzido, para que ocorresse a inoculação por meio da dispersão natural das plantas infectadas para as sadias, com auxílio de ventilação forçada. As avaliações da severidade da doença foram realizadas semanalmente, antes das pulverizações, sempre no período da manhã, utilizando uma escala diagramática proposta por Stadnik et al. (22). Para tanto, foram avaliadas as folhas centrais do terço médio das plantas.

Além da avaliação da severidade foi realizado estudo em microscópio eletrônico de varredura (MEV) para verificar os possíveis mecanismos de ação do bicarbonato de potássio. Foram coletadas cinco folhas de cada tratamento, retirados fragmentos com $0,5 \times 0,5$ $\mathrm{cm}$ que foram imersos em solução fixadora (Karnovisk's modificado), pH 7,2 e armazenado em freezer a $-10^{\circ} \mathrm{C}$ até ser levado para a realização da observação das amostras em microscópio eletrônico de varredura no Laboratório de Microscopia Eletrônica e Análise Ultra-estrutural (LME) do Departamento de Fitopatologia da Universidade Federal de Lavras (UFLA), Lavras, MG. Após o período de fixação o material foi imerso em solução de cacodilato por três vezes por um tempo de 10 minutos em cada imersão, e após este processo foram transferidas para uma solução de tetróxido de ósmio $1 \%$ em água por 1 hora e subsequentemente desidratadas em uma série de acetona $(25,50,75$, 90 e $100 \%$ por três vezes) e depois levadas para o aparelho de ponto crítico. Os espécimes obtidos foram montados em suportes de alumínio ("stubs") com a ajuda de uma fita de carbono dupla face colocada sobre uma película de papel alumínio, cobertos com ouro e observados em microscópio eletrônico de varredura LEO EVO 40XVP.

A análise estatística do experimento foi realizada com base nas médias de cada avaliação. Com a média das cinco avaliações foi calculada a área abaixo da curva de progresso da doença (AACPD). Esses dados foram submetidos ao teste de Scott-Knott, realizado no programa Sisvar $^{\circledR}(8)$, para a comparação de efetividade entre os tratamentos.

\section{RESULTADOS E DISCUSSÃO}

O bicarbonato de potássio, principio ativo do produto Kaligreen ${ }^{\circledR}$, foi eficiente em todas as concentrações, destacando-se as de 0,75 e $1,0 \%$ no controle do oídio da soja em casa de vegetação (Tabela 1 , Figuras 1 e 2). Ao longo do ciclo da cultura foi observado que a intensidade da doença diminuiu gradativamente (Tabela 1). Entretanto, as plantas que receberam 0,$5 ; 0,75$ e $1 \%$ do produto apresentaram fitotoxidez (Figura 2).

Tamm et al. (24), utilizando $0,5 \%$ (v/v) de bicarbonato de potássio no controle da sarna da macieira, observaram que houve redução da doença. Entretanto, quando utilizaram a dosagem de $1 \%(\mathrm{v} / \mathrm{v})$ do produto também verificaram a ocorrência de fitotoxidez. Todavia em trabalhos envolvendo outros patossistemas, o bicarbonato não causou fitotoxicidade, mostrando-se eficaz na redução de doenças em plantas. Oliveira et al. (15) concluíram que a aplicação de leite de vaca in natura na concentração de $50 \mathrm{~mL} / \mathrm{L}$ e $100 \mathrm{~mL} / \mathrm{L}$ e o bicarbonato de sódio na concentração de $4 \mathrm{~g} / \mathrm{L}$ foram eficientes no controle do oídio em moranga, sendo que a severidade da doença permaneceu baixa durante o ciclo da cultura.

Santos (20) verificou que as concentrações de 0,$1 ; 0,2 ; 0,4 ; 0,8$; 1,5 e $3,0 \%(\mathrm{p} / \mathrm{v})$ do produto Kaligreen ${ }^{\circledR}$ reduziram o oídio causado por Podosphaera fusca em abobrinha. As melhores concentrações foram de 1,5 e $0,8 \%$, que controlaram a doença em $87,4 \%$ e $85,1 \%$, respectivamente, quando comparado à testemunha, sendo tão eficiente quanto ao fungicida padrão utilizado, que apresentou $81 \%$ de controle da doença. Entretanto, quando se empregou a concentração de $3 \%(\mathrm{v} /$ $\mathrm{v}$ ), as plantas de abobrinha apresentaram fitotoxidez. O mesmo autor, utilizando sal puro de bicarbonato de potássio $\left(\mathrm{KHCO}_{3}\right)$, nas concentrações de $1 \%$ e $2 \%$, relatou que o sal controlou a doença em $42,8 \%$ e $30,5 \%$, respectivamente. Entretanto, na concentração de $0,5 \%$ do sal, não houve controle da doença. Esses resultados estão de acordo com os obtidos no presente estudo. Lahoz et al. (13) também verificaram redução da severidade de oídio (Erysiphe orontii) em tabaco com o uso de bicarbonato de sódio na dosagem de $10 \mathrm{~g} / \mathrm{L}$, mas não com $5 \mathrm{~g} / \mathrm{L}$. Silicato de potássio líquido, pulverizado sobre plantas de

Tabela 1: Efeito do bicarbonato de potássio $\left(\right.$ Kaligreen $\left.^{\circledR}\right)$ sobre a porcentagem de área foliar afetada por Erysiphe diffusa em plantas de soja mantidas em casa de vegetação.

\begin{tabular}{|c|c|c|c|c|c|}
\hline Tratamento & $\begin{array}{l}1^{\text {a }} \text { avaliação } \\
30^{\circ} \text { dia após }\end{array}$ & $\begin{array}{l}2^{\mathrm{a}} \text { avaliação } \\
38^{\circ} \text { dia após }\end{array}$ & $\begin{array}{l}3^{a} \text { avaliação } \\
44^{\circ} \text { dia após }\end{array}$ & $\begin{array}{l}4^{a} \text { avaliação } \\
51^{\circ} \text { dia após }\end{array}$ & $\begin{array}{l}5^{a} \text { avaliação } \\
58^{\circ} \text { dia após }\end{array}$ \\
\hline $\mathbf{0}$ & $20,85^{*}$ a $\mathrm{D}$ & 31,50 a $\mathrm{C}$ & 41,67 a $B$ & 86,25 a $\mathrm{A}$ & 84,17 a $\mathrm{A}$ \\
\hline $0,50 \%$ & $3,43 \mathrm{~b} \mathrm{~A}$ & $4,65 \mathrm{~b} \mathrm{~A}$ & $10,75 \mathrm{c} \mathrm{A}$ & 7,43 с A & $10,55 \mathrm{c} \mathrm{A}$ \\
\hline $0,75 \%$ & $4,22 \mathrm{~b} \mathrm{~A}$ & $5,23 \mathrm{~b} \mathrm{~A}$ & $2,50 \mathrm{c} \mathrm{A}$ & $2,75 \mathrm{c} \mathrm{A}$ & $0,60 \mathrm{~d} \mathrm{~A}$ \\
\hline
\end{tabular}

*Médias seguidas de mesma letra minúscula na coluna e pela mesma letra maiúscula na linha não diferem estatisticamente (p>0,05) - Teste de Scott Knott. A primeira avaliação foi realizada no $30^{\circ}$ dia após a emergência e as demais no $38^{\circ}, 44^{\circ}, 51^{\circ}$ e $58^{\circ}$ dia após a emergência. 

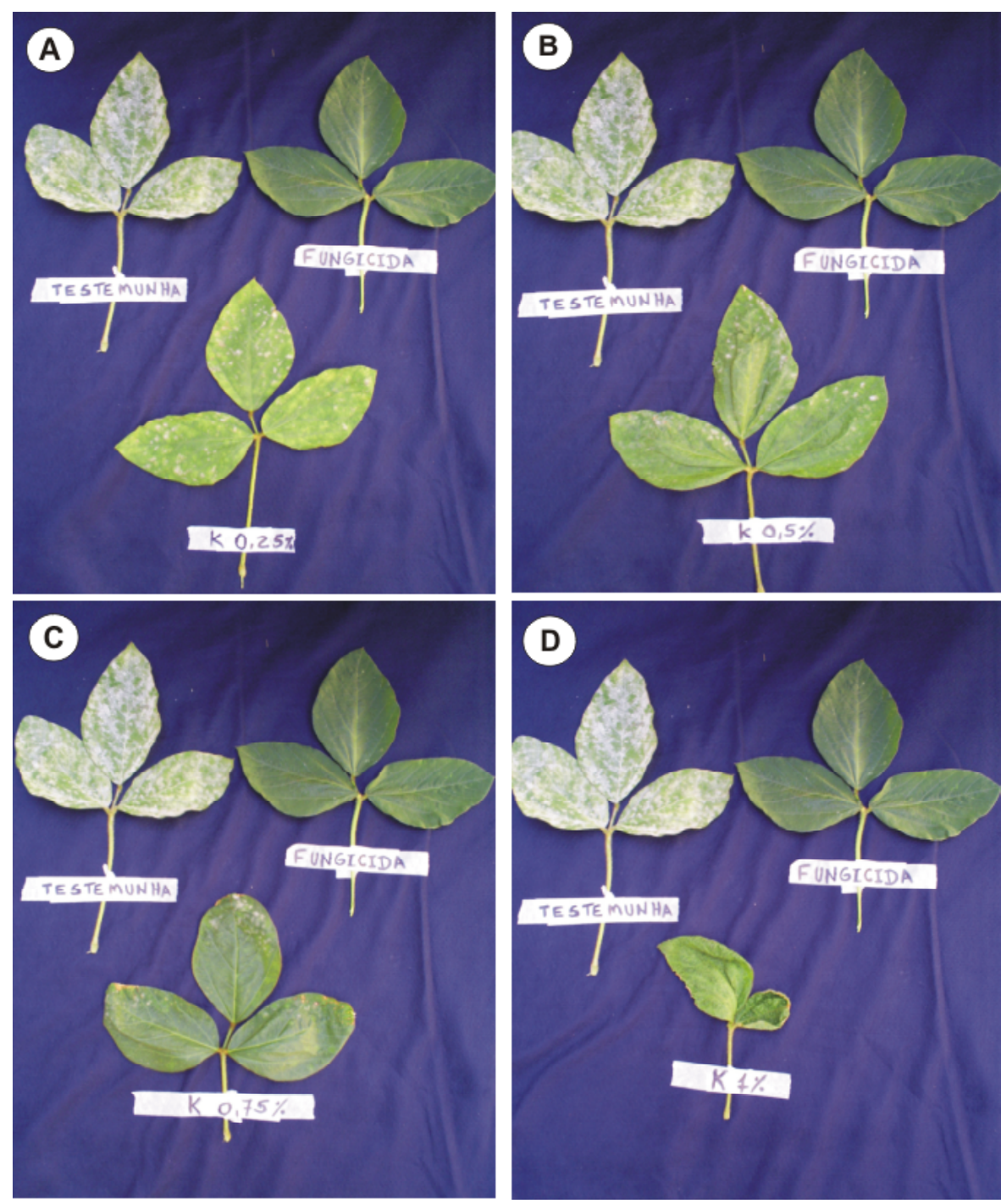

Figura 1. Efeito do bicarbonato de potássio (Kaligreen $^{\circledR}$ ) nas concentrações de $0,25 \%$ (A), 0,5\% (B), 0,75\% (C) e $1 \%$ (D) no controle de Erysiphe diffusa na cultivar MG/BR 46 (Conquista) de soja.

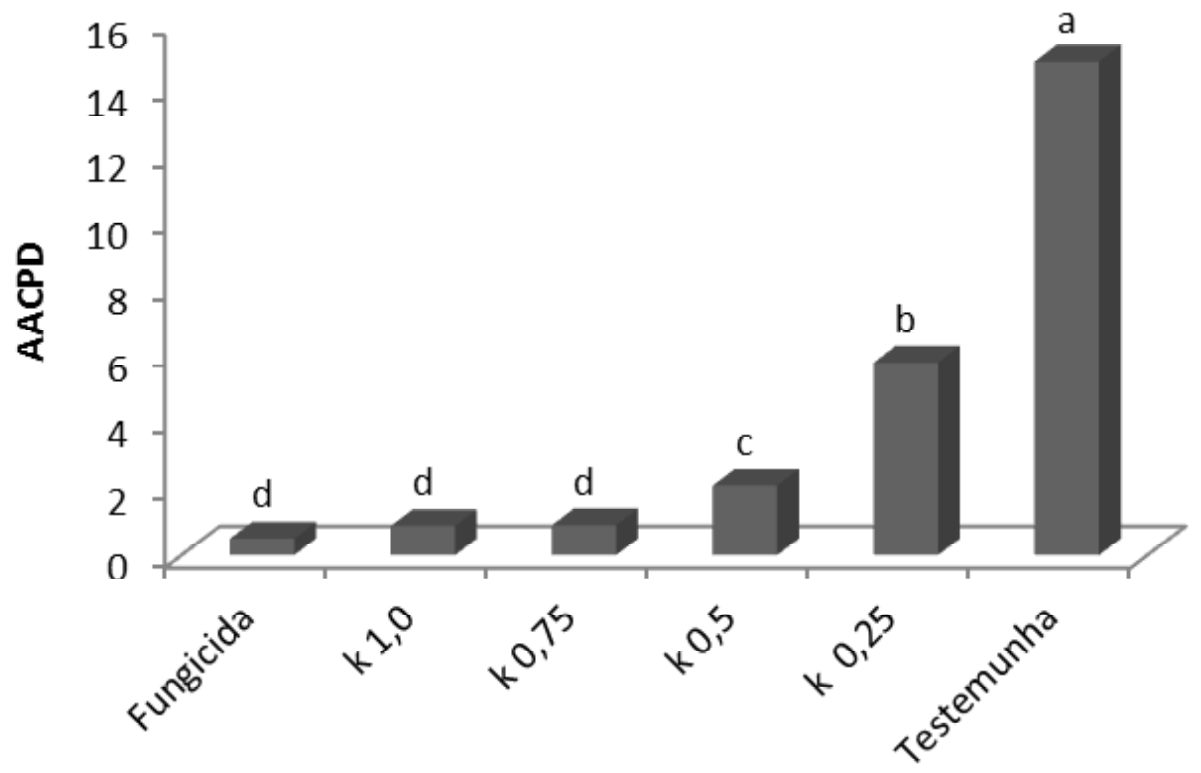

Figura 2 - Efeito do Kaligreen ${ }^{\circledR}$ sobre a área abaixo da curva de progresso da doença (AACPD) causada pelo oídio (Erysiphe diffusa) em soja. Médias seguidas de mesma letra não diferem entre si. 
morango, controlou o oídio. Essa informação é importante, pois demonstra que esse sal combinado com outra substância pode apresentar um resultado satisfatório como o observado por Kanto et al. (12).

Os resultados obtidos com os bicarbonatos indicam que apresentam potencial para controlar oídios. Entretanto, mesmo utilizando dosagens reduzidas, pode ocorrer problemas de fitotoxicidade. Mesmo diante do problema da fitoxicidade, os carbonatos e bicarbonatos tem se mostrado eficazes contra várias doenças, como por exemplo, os observados por Anônimo (1) que verificou que os carbonatos foram eficazes no controle do mofo cinzento da videira, reduzindo a germinação dos esporos de Botrytis cinerea, enquanto que, o bicarbonato de sódio e bicarbonato de amônio foram mais eficazes que o bicarbonato de potássio na redução da doença. Assim, é importante realizar estudos determinando as concentrações adequadas e a frequência de aplicação desses produtos que controlem a doença sem causar problemas de fitotoxicidade. Deve-se também considerar que os estudos foram realizados em cultivo protegido, sendo que nessas condições os problemas de fitotoxicidade são assentuados. Assim, os estudos devem ser repetidos em condições de campo.

Nas observações realizadas em microscopia eletrônica de varredura, verificou-se que nas folhas provenientes das plantas testemunhas (Figuras 3A e 3B) os conídios germinaram normalmente, enquanto que o bicarbonato de potássio, nas diversas concentrações, apresentou efeito direto sobre o patógeno, ocasionando murchamento dos conídios (Figuras 3C, 3D e 3E). Na concentração a 1\% de bicarbonato de potássio (Figura 3F) houve redução na formação de conídios, observando, nas folhas dessas plantas, diminuição na esporulação e ausência de germinação quando comparados à testemunha (Figuras 3A e 3B). Esses resultados indicam que o possível modo de ação do bicarbonato seja na inibição direta do patógeno.

Diante dos resultados deste trabalho, o que se conclui é que o bicarbonato de potássio é eficiente no controle de oídio em soja. Entretanto, futuras pesquisas deverão ser realizadas no intuito de adequar dosagens e frequência de aplicação para que não causem fitotoxicidade e controlem adequadamente a doença.
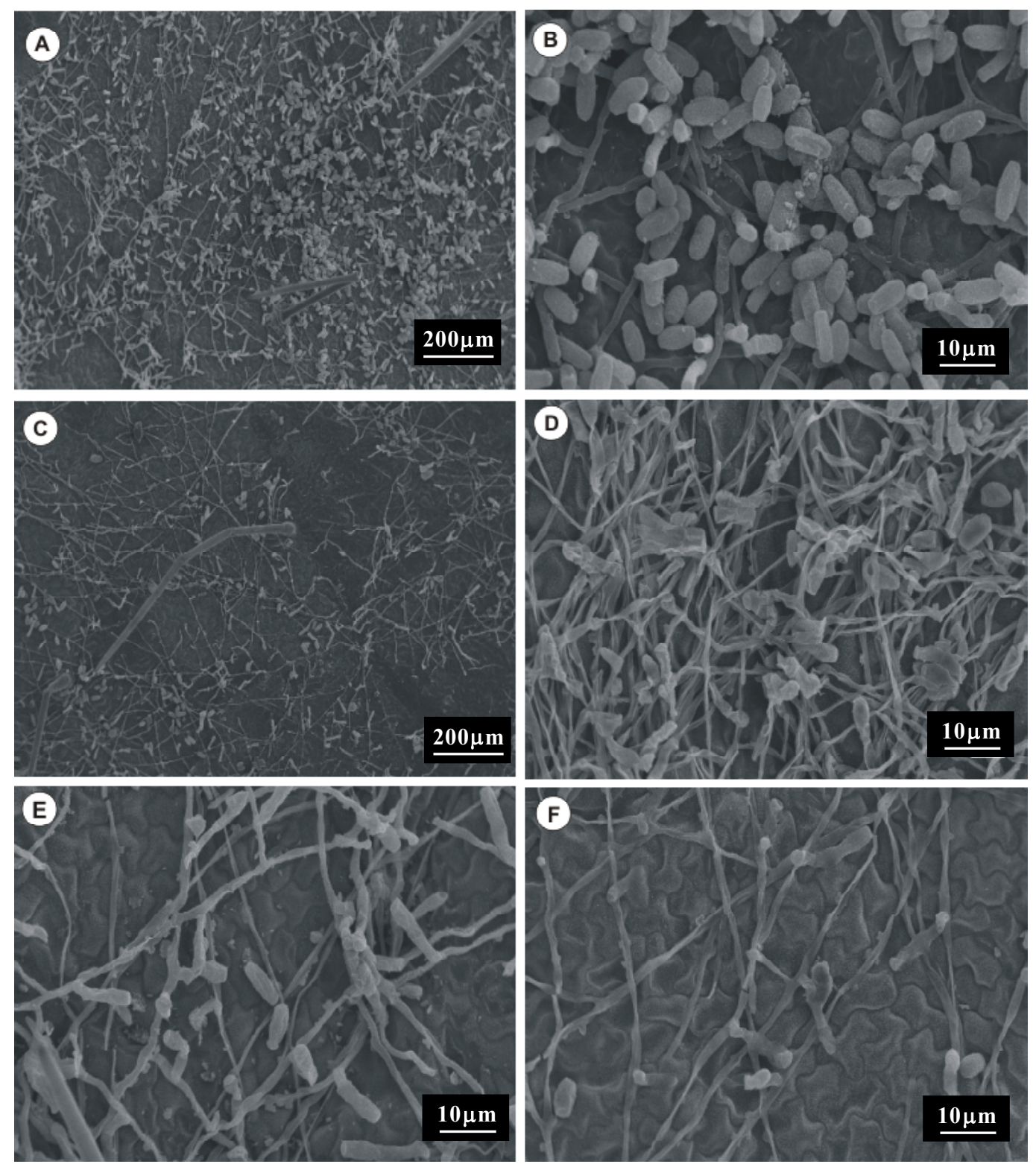

Figura 3. Eletromicrografias de varredura de folhas de soja infectadas com Erysiphe diffusa, mantidas em casa de vegetação, e tratadas com água (A e B) e com bicarbonato de potássio (Kaligreen ${ }^{\circledR}$ ) nas concentrações de 0,25 (C); 0,50 (D); 0,75 (E) e 1\% (F) (v/v). 


\section{REFERÊNCIAS BIBLIOGRÁFICAS}

1. Anônimo. Baking soda and gray mold. Conference notes: ESA and APS joint meeting. IPM Practitioner. April. p. 10-11, 1999.

2. Bettiol, W. Productos alternativos para el control del oídio (Sphaerotheca fuliginea) de la calabaza. In: CONGRESSO NACIONAL DE LA SOCIEDAD ESPAÑOLA DE FITOPATOLOGIA, 8., 1996, Córdoba. Anais... Córdoba, p. 232, 1996.

3. Bettiol, W. \& Astiarraga, B.D. Controle de Sphaerotheca fuliginea em abobrinha com resíduo da fermentação glutâmica do melaço e produto lácteo fermentado. Fitopatologia Brasileira, v.22, p. 431-435, 1998

4. Bettiol, W.; Astiarraga, B.D.; Luiz, A.J.B. Effectiveness of cow's milk against zucchini squash powdery mildew (Sphaerotheca fuliginea) in greenhouse conditions. Crop Protection, v.18, p. 489492, 1999

5. Bettiol, W.; Silva, S.H.A.; Ronielli, R.C. Effectiveness of whey against zucchini squash and cucumber powdery mildew. Scientia Horticulturae, v.117, p. 82-84, 2008

6. Embrapa. Disponível no site: http://sistemasdeproducao. cnptia.embrapa.br/FontesHTML/Soja/SojaCentralBrasil2003/ doenca.htm. Acesso em outubro de 2010, 2003.

7. Ferradino, F.J.; Smith, V.L. The effect of milk-based foliar sprays on yield components of field pumpkins with powdery mildew. Crop Protection, v.26, p. 657-663, 2007.

8. Ferreira, D.F. Análise estatística por meio do SISVAR para Windows versão 4.0. In: Reunião anual da região brasileira da sociedade internacional de biometria, 45, 2000, São Carlos. Programas e Resumos... São Carlos, SP: UFSCar. p.235, 2000.

9. Garibaldi, A,; Aloi, A.; Minuto, A. Osservazioni sull'attivita di prodotti fosfatici nei riguardi di Erysiphe sp. su pomodoro in coltura protteta. ATTI Gionarle Fitopatologiche, v.3, p. 245 250,1994

10. Homma, Y.; Arimoto, Y.; Misato, T. Effect of sodium bicarbonate on each growth stage cucumber powdery mildew fungus (Sphaerotheca fuliginea) in its life cycle. Journal of Pesticide Science, v.6, p. 201-209, 1991.

11. Horst, R.K.; Kawamoto, S.O.; Porter, L.L. Effect of sodium bicarbonate and oils on the control of powdery mildew and black spot of roses. Plant Disease, v.76, p. 247-251, 1992.

12. Kanto, T.; Miyoshi, A.; Ogawa, T.; Maekawa, K.; Aino, M. Suppressive effect of liquid potassium silicate on powdery mildew of strawberry in soil. Journal General Plant Pathology, v.72, p. $137-$ 142,2006

13. Lahoz, E.; Contillo, R.; Porrone, F.; Avigliano, M.; Iovieno, P. Efficacy of rue extract, sodium bicarbonate and fungicides at reduced rates to control of powdery mildew on tobacco. Il Tabacco, v.9, p. 57-65, 2001.

14. Marco, S.; Ziu, O.; Cohen, R. Suppression of powdery mildew in squash by applications of whitewash, clay and antitranspirant materials. Phytoparasitica, v.22, p. 19-29, 1994.

15. Oliveira, V.R.; Gianasi, L.; Mascarenhas, M.H.T.; Pires, N.M.; Filho, J.A.A.; Viana, M.C.M.; Lara, J.F.R. Controle de oídio em moranga híbrida. Horticultura Brasileira, Brasília, DF, v. 20, n. 2 , p. 267, jul. 2002. Suplemento 1.

16. Pasini, C.; D'Aquila, F.; Curir, P.; Gullino, M.L. Effectiveness of antifungal compounds against rose powdery mildew (Sphaerotheca pannosa var. rosae) in glasshouses. Crop Protection, Surrey, v. 16, n. 3, p. 251-256, 1997.

17. Pereira, J.C.R.; Zambolim, L.; Chaves, G.M.; Costa, H.; Ribeiro do Vale, F.X.R. Controle de oídio do pepino pelo uso de bicarbonato de sódio em condições de casa de vegetação. Fitopatologia Brasileira, v.20, p. 359, 1995

18. Reuveni, M.; Agapov, V.; Reuveni, R. Suppression of cucumber powdery mildew (Sphaerotheca fuliginea) by foliar sprays of phosphate and potassium salts. Plant Pathology, v.44, p. 31-39, 1995.

19. Reuveni, M.; Agapov, V.; Reuveni, R Controlling powdery mildew caused by Sphaerotheca fuliginea in cucumber by foliar sprays of phosphate and potassium salts. Crop Protection, v.15, p. 49-53, 1996.

20. Santos, A.P. Controle do oídio da abobrinha com antagonistas e produtos biocompatíveis. 2009. 55 p. Dissertação (Mestrado em Fitopatologia) - Universidade Federal de Lavras, 2009.

21. Sinclair, J.B. \& Backman, P.A. Compendium of soybean disease 3 ed. St Paul: APS Press, 106p, 1999.

22. Stadnik, M.J.; Kobori, R.F.; Bettiol, W. Oídios de cucurbitáceas. In: Stadnik, M.J. e Rivera, M.C. (Eds.). Oídios. Jaguariúna-SP Embrapa Meio Ambiente, 2001. p.217-254.

23. Stadnik, M.J.; Bettiol, W.; Saito, M.L. Bioprospecting for plant and fungus extracts with systemic effect to control the cucumber powdery mildew. Journal of Plant Diseases and Protection, v.110, p. 383-393, 2003.

24. Tamm, L.; Amsler, T.; Scharer, H.; Refardt, H.M. Efficacy of Armicarb (potassium bicarbonate) against scab and sooty blotch on apples. Proceedings of the 12 th International Conference on cultivation technique and phytopathological problems in organic fruit-growing, ed. (FÖKO and Weinsberg) 87-92, 2006.

25. Yorinori, J.T. Situação atual das doenças potenciais no Cone Sul In: CONGRESSO BRASILEIRO DE SOJA, 2., Foz do Iguaçu, PR Anais, Congresso Brasileiro de Soja, Londrina: Embrapa Soja, 2002 .

26. Ziv, O. \& Zitter, T.A. Effects of bicarbonates and film-forming polymers on cucurbit foliar diseases. Plant Disease, v.76, p. 513517,1992

27. Ziv, O. \& Hagiladi, A. Controlling powdery mildew in euonymus with polymer coatings and bicarbonate solutions. HortScience, v.28, p. 124-126, 1993. 